\title{
MENINGKATKAN PEMAHAMAN BACA SISWA DENGAN REVIEW MENGGUNAKAN TEKNIK ISHIKAWA FISHBONE DI SMPN 1 TAJURHALANG BOGOR
}

\author{
Aprillia Putri Lisdawati. \\ aprilliaputrilis@gmail.com \\ Mahasiswa Fakultas Keguruan dan Ilmu Pendidikan
}

\begin{abstract}
ABSTRAK
Memahami isi bacaan adalah hal terpenting dalam membaca. Namun, pemahaman siswa akan bacaannya masih sangat rendah. Mereview adalah salah satu cara yang dapat digunakkan dalam memahami isi bacaan. Salah satu teknik review yang dapat membuat siswa memahami bacaannya ialah teknik Ishikawa Fishbone. Teknik ini dapat membantu siswa dalam mengidentifikasi identitas buku, jenis bacaan dan grammatika maupun penambahan vocabulary (kosa kata bahasa inggris) siswa. Penelitian ini melibatkan 5 responden yang berasal dari kelas 9 di SMPN 1 Tajurhalang Bogor, dengan beberapa tahapan yaitu penjelasan, praktik pembuatan dan interview. Responden memiliki tanggapan yang sangat beragam, tetapi memiliki kecenderungan yang sama yaitu teknik Ishikawa Fishbone dapat membantu mereka dalam memahami bacaannya.
\end{abstract}

Kata Kunci: SMPN 1 Tajurhalang Bogor, Teknik Ishikawa Fishbone, Meningkatkan Pemahaman Baca.

\section{PENDAHULUAN}

Membaca adalah kegiatan untuk memperoleh informasi maupun ilmu pengetahuan. Imron Rosidi (2015) mengatakan bahwa membaca adalah jembatan yang mampu menghubungkan kita dengan segala jenis ilmu pengetahuan yang ada di muka bumi. Namun, minat baca yang dimiliki siswa pada saat ini sangatlah rendah. Berdasarkan studi Most Littered Nation in the world pada tahun 2016 minat baca di Indonesia menduduki peringkat 60 dari 61 negara. Hal ini menjadikan Indonesia sebagai negara yang minim akan aktivitas membaca. Menurut Imron Rosidi (2015), "salah satu penyebab minimnya minat baca siswa ialah perasaan bosan yang sering muncul ketika siswa membaca". Hal ini disebabkan karena kurangnya pemahaman siswa akan isi dari bacaannya. Untuk meningkatkan pemahaman baca siswa, review menjadi tools (alat) yang sesuai dalam membantu siswa memahami apa yang telah ia baca (Wainwraight, 2007). Salah satu teknik review yang dapat membantu siswa dalam memahami isi bacaannya ialah teknik Ishikawa fishbone. Menurut Krus (2010) "teknik fishbone dapat mempermudah dalam memperoleh informasi, mengaplikasikan ide-ide baru dan mencari hubungan antar bacaan tersebut (sebab) serta petunjuknya (akibat)." Nasir (2014) mengatakan bahwa Ishikawa fishbone merupakan suatu alat untuk memahami dan mengorganisir suatu informasi. Penggunaan teknik review Ishikawa fishbone ini tidak hanya sebagai alat yang dapat membantu siswa untuk memahami isi bacaannya tetapi teknik ini juga dapat membantu siswa untuk meningkatkan kreatifitasnya. Menurut salah satu guru mata pelajaran bahasa Indonesia yang sudah menerapkan teknik Ishikawa Fishbone di SMPN 1 Tajurhalang, Susi Sulistyawati, S.Pd mengatakan bahwa 
teknik ini tidak hanya digunakan untuk memahami bacaan tetapi dengan teknik ini siswa dapat meningkatkan kreativitasnya.

Ishikawa fishbone merupakan teknik yang diproklamirkan oleh Kauro Ishikawa untuk mengatasi masalah pengendalian mutu kualitas dengan menentukan dampak serta akibat dengan metode fishbone diagram (Martin,2006). Metode ini dinamakan diagram fishbone karena berbentuk mirip dengan tulang ikan yang moncong kepalanya menghadap kekanan (Bose,2012). Diagram ini akan menunjukkan sebuah dampak atau akibat dari suatu permasalahan dengan berbagai penyebabnya. Efek atau akibat dituliskan sebagai moncong kepala. Sedangkan tulang ikan diisi oleh sebab-akibat sesuai dengan pendekatan permasalahannya. Karena inilah diagram fishbone ishikawa

\section{METODE PENELITIAN}

Penelitian ini kami lakukan dengan mengumpulkan data berdasarkan perspektif responden dalam interview yang merupakan salah satu jenis pengumpulan data yang terdapat dalam metode penelitian kualitatif. Peneltian dilakukan melalui 3 tahapan dengan kurun waktu 1 minggu yaitu pada tanggal 11- 18 November 2017 di lingkungan SMPN 1 Tajurhalang.

Pada tahap pertama, kami mengumpulkan 5 responden yang berasal dari kelas 9. Kelima responden tersebut tidak asing dengan penggunaan Ishikawa fishbone karena program literasi yang sudah dilaksanakan oleh pihak sekolah. Tetapi kami mencoba menerapkan hal yang berbeda dengan sebelumnya. Jika ini dikenal juga sebagai diagram sebab dan akibat. Teknik tersebut dapat membantu para pekerja dalam merumuskan permasalahannya.

Teknik ishikawa fishbonepun berkembang didunia literasi dengan memanfaatkannya untuk mereview sebabakibat suatu cerita dengan mengungkapkan unsur instrinsik alurnya sebagai sebab dan hikmah atau amanat cerita sebagai dampak yang dirasakan. Oleh karena itu kami percaya jika teknik review ishikawa fishbone ini dapat meningkatkan pemahaman siswa dalam membaca.

Tujuan dari penelitian ini ialah untuk mengetahui pengaruh mereview dengan menggunakan teknik Ishikawa Fishbone terhadap kemampuan siswa dalam memahami bacaannya.

sebelumnya siswa diminta untuk mereview buku berbahasa Indonesia dan menggunakan bahasa Indonesia, kami meminta agar siswa dapat mereview bacaan text Bahasa Inggris dan menggunakan bahasa Inggris. Serta menambahkan beberapa unsur materi sesuai dengan apa yang dibutuhkan siswa dalam memahami bacaan, seperti identitas buku, jenis text bacaan, jenis grammatika dan kosa kata. Sehingga pemahaman siswa akan bacaannya menjadi menyeluruh, tidak hanya mampu untuk memahami cerita tetapi juga mampu memahami jenisjenis teks, grammar, identitas buku serta dapat menambah kosa kata baru. Berikut merupakan hasil modifikasi fishbone yang kami lakukan. 


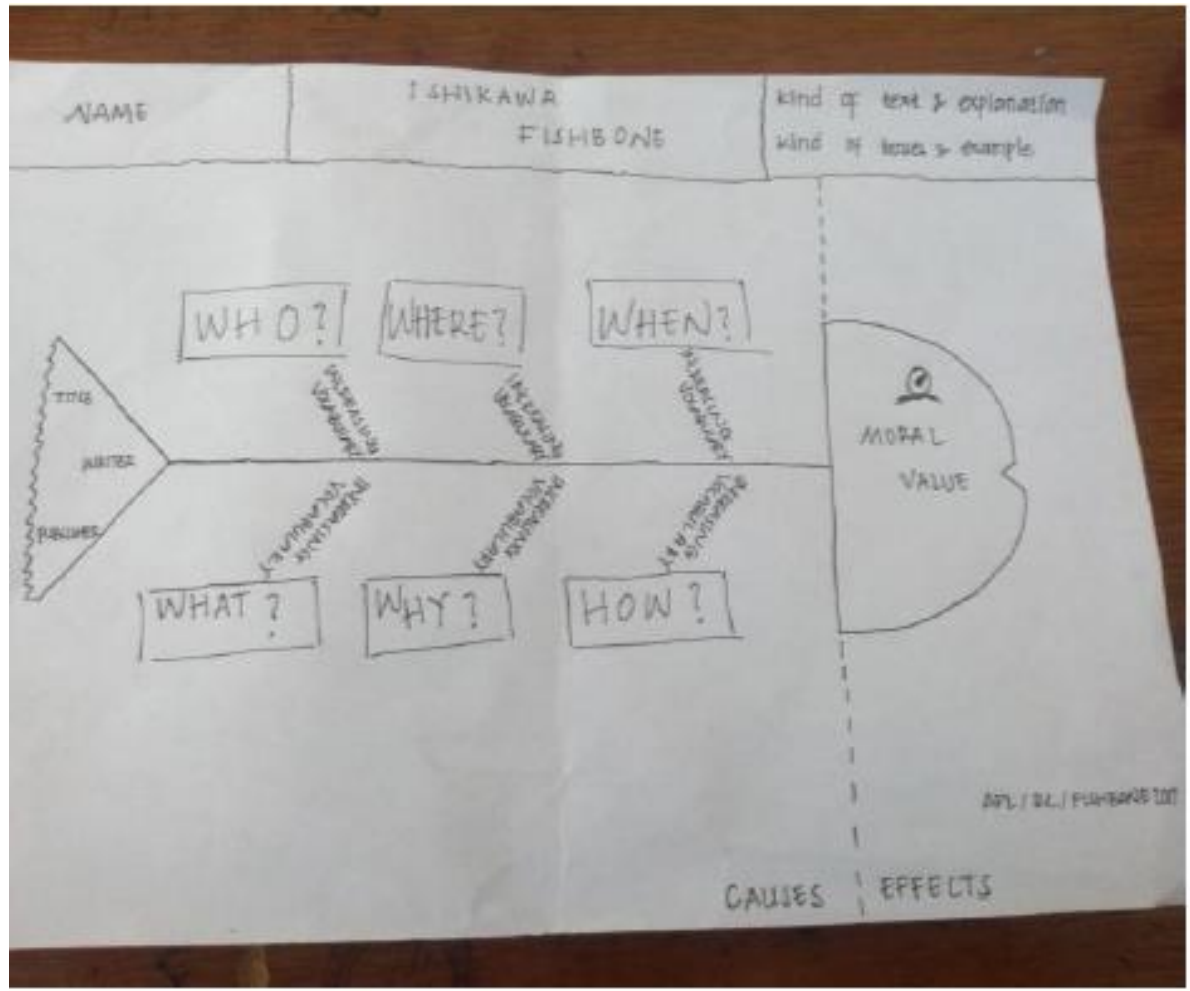

Selanjutnya, kami menyediakan sumber bacaan yang akan siswa review dengan menggunakan teknik tersebut. Buku yang kami gunakan ialah AEOSOP $^{\text {ee }}$ S Fabel terbitan Indonesia. Buku ini terdiri dari 5 bagian cerita dengan masingmasing jumlah kata terdiri dari 350400 kata. Siswa dapat menentukan sendiri fabel apa yang akan mereka review nantinya. Kami meminta kelima siswa tersebut untuk membuat review Ishikawa fishbone selama 5 hari untuk memahami point-point yang diminta seperti isi bacaan (5W+1H dan Moral Value), identitas buku, kind of text and tenses and increasing vocabularies. Sedangkan untuk tahap akhir (Menggambar dan menghias) dilakukan bersama. Kami juga mengadakan award untuk memotivasi siswa agar maksimal dalam pengerjaannya. Menurut Munawir Yusuf (2003), "Kebutuhan untuk berprestasi adalah dorongan dari dalam diri individu untuk melakukan segala sesuatu dengan baik, antara lain dengan mengatasi rintangan, menyelesaikan tugas dengan baik dan mencapai derajat keberhasilan yang tinggi". Pemberian award dapat menjadi apresiasi kepada siswa terhadap prestasinya, agar selalu melakukan hal terbaik dan memaksimalkan diri.

Tahap kedua, ditahap kedua ini siswa mulai mempraktikan untuk membuat ishikawa fishbone. Setelah mereka menemukan point-point penting yang terdapat dalam bacaan. Mereka memulai pembentukan fishbone atau diagram ikan dengan menggambar kerangka tulang ikan lalu diisi oleh point-point tersebut dengan urutan buntut ikan diisi oleh judul cerita, penulis dan penerbit buku, cabang tulang ikan sebagai increasing vocabularies dan dihubungkan dengan 5W(What, Who, Where, When and Why) dan How serta dibagian kepala diisi oleh Moral value (Hikmah cerita). Setelah itu, siswa dapat bebas mengkreasikan fishbone yang telah mereka buat tanpa kami batasi. Sehingga membuat mereka bebas untuk mengekspresikan kreatifitas yang mereka miliki. Berikut adalah hasil fishbone yang telah siswa buat. 

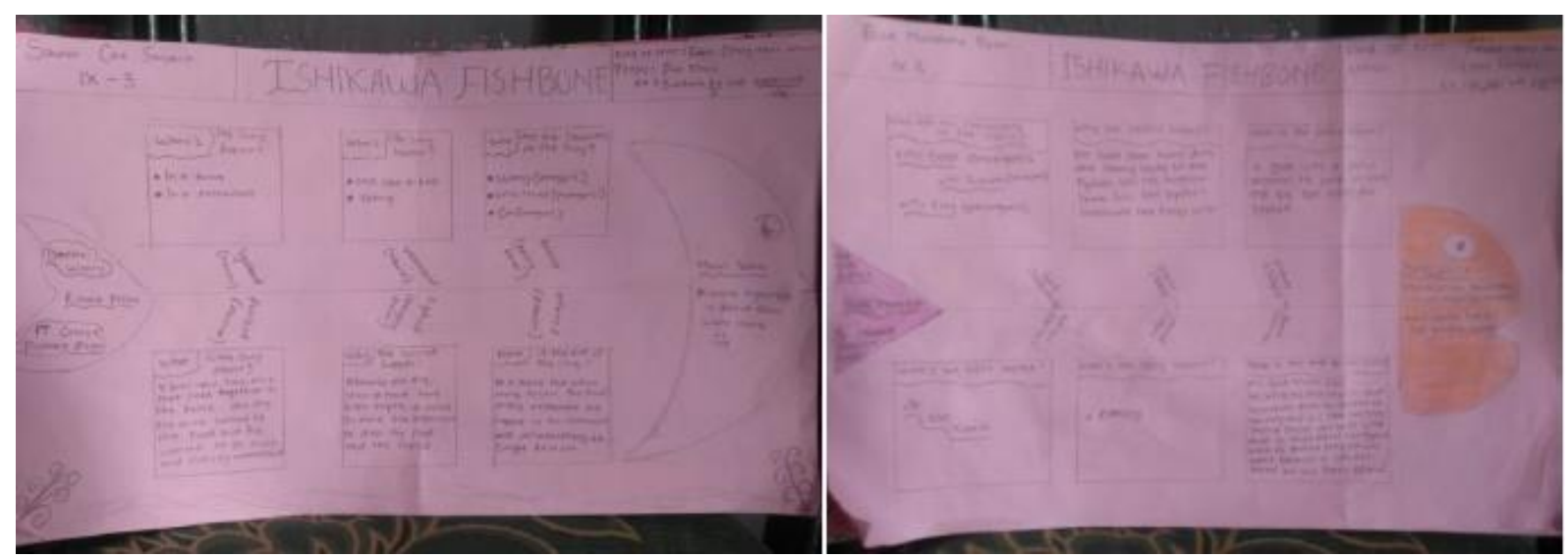

Responden 1 dan 2
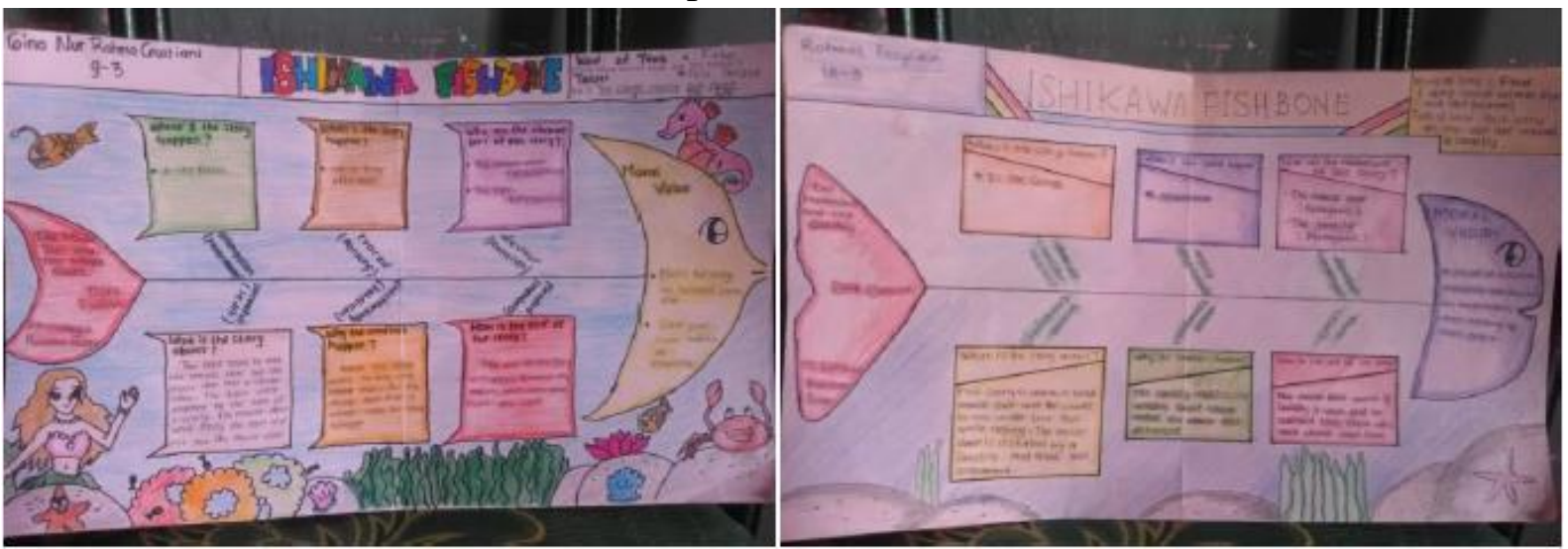

Responden 3 dan 4

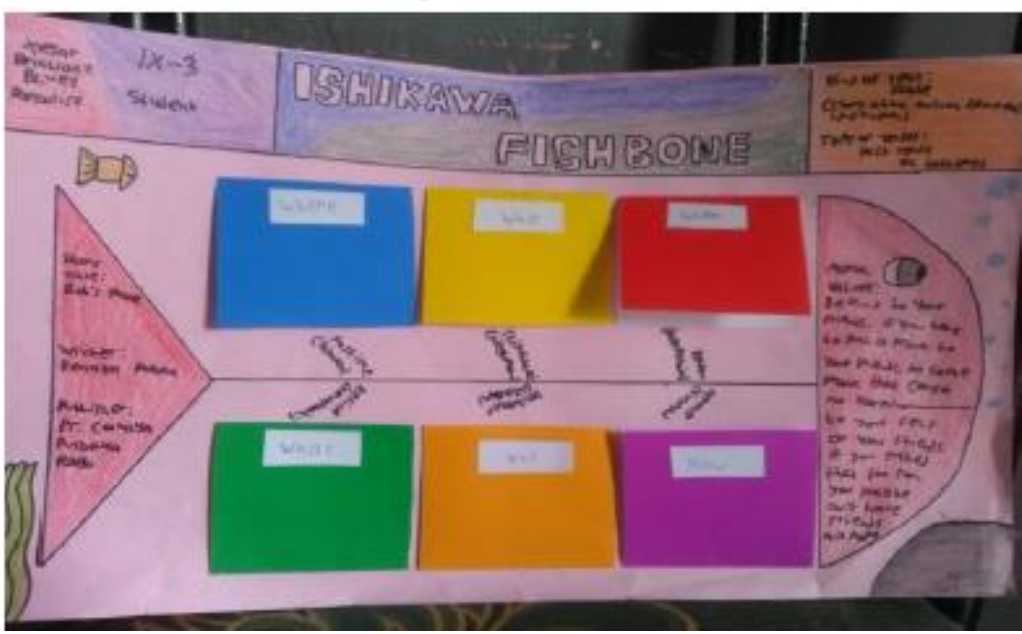

Responden 5

Foto 1-5 : Ishikawa Fishbone yang sudah dibuat oleh siswa

Tahap ketiga, yaitu tahap interview. Jenis interview yang kami gunakan ialah semi-scructured interview. Semi-structured interview ialah jenis interview yang menggunakan beberapa pertanyaan yang telah ditentukan dengan jawaban berupa opini responden (M.Easwaramorty,2006). dalam interview ini kami memberikan beberapa pertanyaan berkaitan dengan penggunaan Ishikawa Fishbone dengan jawaban yang berasal dari opini mereka setelah menerapkan teknik ishikawa fishbone. Sebelum melakukan interview, kami meminta responden untuk 
menjelaskan terlebih dahulu isi cerita dari bacaan yang sudah direview oleh mereka. Hal ini dilakukan untuk mengukur apakah siswa mengerti dengan isi bacaannya. Menurut Wainwright (2007),'dengan

\section{HASIL PENELITIAN}

Interview sebagai cara dalam pengumpulan data yang kami lakukan, menjadi tahap akhir dalam penelitian ini. Interview dilakukan setelah siswa menyelesaikan fishbone yang telah mereka buat dan hias. Sebelum melakukan interview saya berdiskusi dan menyampaikan isi cerita yang kita baca kepada orang lain serta mampu membuat orang lain mengerti akan apa yang kita ceritakan dapat menjadi tolak ukur akan pemahaman cerita."

1. Mengapa anda memilih cerita tersebut untuk direview ?

\begin{tabular}{|c|c|c|}
\hline Responden ke- & Judul fabel yang dipilih & Judul fabel yang dipilih \\
\hline 1 & The Goat Secret & $\begin{array}{l}\text { Saya memilih fable ini } \\
\text { karena } \\
\text { memiliki Jumlah kata yang } \\
\text { sedikit dibanding cerita } \\
\text { lain }\end{array}$ \\
\hline 2 & Boastful Wenny & $\begin{array}{l}\text { Saya memilih cerita ini } \\
\text { karena memiliki amanat } \\
\text { atau hikmah cerita yang } \\
\text { menarik }\end{array}$ \\
\hline 3 & $\begin{array}{l}\text { The Mouse Deer and the } \\
\text { Magic Flute }\end{array}$ & $\begin{array}{l}\text { Saya memilih fabel ini } \\
\text { karena ceritanya jarang } \\
\text { didengar } \\
\text { dibandingkan orang } \\
\text { fabel-fabel lainnya seperti } \\
\text { kancil dan buaya, kancil } \\
\text { dan keong dan yang } \\
\text { lainnya. }\end{array}$ \\
\hline 4 & $\begin{array}{l}\text { The Mouse Deer and The } \\
\text { Sandfly }\end{array}$ & $\begin{array}{l}\text { cerita ini belum pernah } \\
\text { saya dengar sebelumnya, } \\
\text { sehingga membuat saya } \\
\text { penasaran }\end{array}$ \\
\hline 5 & Bob $^{\text {ee }}$ Prank & $\begin{array}{l}\text { saya belum pernah } \\
\text { mendengar cerita ini, selain } \\
\text { itu amanat yang dapat } \\
\text { diambil dari cerita ini juga } \\
\text { sangat bagus }\end{array}$ \\
\hline
\end{tabular}


2. seberapa paham anda dengan cerita yang anda review? Gambarkan dalam bentuk persen $(\%)$ !

\begin{tabular}{|l|l|}
\hline Responden ke- & Persentase pemahaman siswa akan bacaannya \\
\hline 1 & $80 \%$ \\
\hline 2 & $80 \%$ \\
\hline 3 & $90 \%$ \\
\hline 4 & $90 \%$ \\
\hline 5 & $75 \%$ \\
\hline
\end{tabular}

3. Apakah pemahaman tersebut muncul hanya dengan membaca ceritanya saja atau setelah anda mereview isi bacaan tersebut dengan point-point yang terdapat di Ishikawa Fishbone?

\begin{tabular}{|l|l|}
\hline Responden ke- & \multicolumn{1}{|c|}{ Jawaban } \\
\hline 1 & $\begin{array}{l}\text { Menurut saya membaca saja tidaklah cukup, oleh karena itu review yang } \\
\text { terdapat dalam Ishikawa fishbone sangat membantu saya dalam } \\
\text { memahami isi bacaan }\end{array}$ \\
\hline 2 & $\begin{array}{l}\text { Tidak, saya baru mengerti isi cerita ketika saya harus mencari unsur } \\
\text { intrinsik dalam cerita tersebut dan hal tersebut ada di Ishikawa fishbone }\end{array}$ \\
\hline 3 & $\begin{array}{l}\text { Setelah membaca cerita ini saya mengerti, tetapi saya hanya menangkap } \\
\text { alur dari cerita ini tidak sampai mengetahui hikmah cerita, identitas buku } \\
\text { dan hal lainnya. Jadi, dengan mereview menggunakan teknik ishikawa } \\
\text { fishbone saya dapat mengerti isi bacaan secara menyeluruh dan lengkap } \\
\text { karena terdapat pointpoint lain seperti identitas buku, jenis text serta } \\
\text { penambahan kosa kata baru }\end{array}$ \\
\hline 4 & $\begin{array}{l}\text { Saya harus membaca cerita ini berulang-ulang untuk mengerti dan } \\
\text { mentranslatekannya kedalam bahasa yang saya pahami(Indonesia) dengan } \\
\text { adanya increasing vocabulary membantu saya dalam menuliskan kata- } \\
\text { kata bahasa inggris yang saya tidak mengerti. }\end{array}$ \\
\hline 5 & $\begin{array}{l}\text { Saya sedikit bingung untuk memahami isi bacaan karena menggunakan } \\
\text { bahasa inggris. Tetapi dengan adanya point point yang terdapat di } \\
\text { Ishikawa fishbone dapat membantu saya menemukan alur sebenarnya dari } \\
\text { cerita yang saya baca }\end{array}$ \\
\hline
\end{tabular}

4. Apa pendapatmu tentang Ishikawa fishbone?

\begin{tabular}{|l|l|}
\hline Responden ke- & Jawaban \\
\hline 1 & $\begin{array}{l}\text { Diagram penolong yang dapat membantu kita lebih paham akan } \\
\text { bacaan tersebut }\end{array}$ \\
\hline 2 & $\begin{array}{l}\text { Ishikawa fishbone tidak membosankan untuk dilihat sehingga dapat } \\
\text { menarik orang untuk membacanya serta kreatif karena kita diminta } \\
\text { untuk menghias diagram tersebut }\end{array}$ \\
\hline 3 & $\begin{array}{l}\text { Ishikawa fishbone itu mempermudah isi bacaan karena terdapat point- } \\
\text { point yang dapat membantu kita memahami isi bacaan }\end{array}$ \\
\hline 4 & $\begin{array}{l}\text { Ishikawa fishbone dapat mempermudah memahami isi bacaan karena } \\
\text { strukturnya lengkap }\end{array}$ \\
\hline 5 & $\begin{array}{l}\text { Peta konsep seperti mind mapping tapi memiliki bentuk yang berbeda } \\
\text { yaitu tulang ikan serta memiliki unsur-unsur yang lengkap }\end{array}$ \\
\hline
\end{tabular}


5. apakah teknik ini dapat membantu anda dalam memahami isi bacaan? Serta manfaat apa saja yang kamu dapatkan dengan teknik review ini?

\begin{tabular}{|c|l|}
\hline Responden ke- & \multicolumn{3}{|c|}{ Jawaban } \\
\hline 1 & $\begin{array}{l}\text { Sangat membantu, karena salah satu point didalam ishikawa } \\
\text { fishbone kami diminta untu mencari kosa kata baru dan } \\
\text { menuliskannya, hal tersebut membuat kami paham akan cerita } \\
\text { tersebut serta dapat meningkatkan vocabulary kami }\end{array}$ \\
\hline 2 & $\begin{array}{l}\text { Membantu, karena dengan teknik review ini memiliki tampilan } \\
\text { yang menarik sehingga membuat orang lain tertarik untuk } \\
\text { membaca dan membuatnya. Selain untuk memahami bacaan } \\
\text { teknik ini juga mampu meningkatkan kreativitas kami. }\end{array}$ \\
\hline 3 & $\begin{array}{l}\text { Sangat membantu, selain dapat memahami isi cerita kami juga } \\
\text { dapat mengetahui jenis text serta tenses sehingga dapat } \\
\text { menambah pemahaman kami tentang hal tersebut }\end{array}$ \\
\hline 4 & $\begin{array}{l}\text { Sangat membantu, karena ishikawa fishbone memiliki point } \\
\text { yang lengakap, seperti identitas buku jenis text dan tenses } \\
\text { sehingga membuat pemahaman kami terhadap bacaan tersebut } \\
\text { lebih menyeluruh }\end{array}$ \\
\hline 5 & $\begin{array}{l}\text { Sangat membantu, karena ishikawa fishbone dapat } \\
\text { mempermudah kami memahami bacaan dengan mencari point- } \\
\text { point yang diminta serta dapat meningkatkan vocabulary kami. }\end{array}$ \\
\hline
\end{tabular}

\section{PEMBAHASAN}

Dari hasil interview tersebut terdapat beberapa kesimpulan dari setiap point yang ditanyakan yaitu sebagai berikut, hasil interview pertanyaan ke- 1 , menunjukkan bahwa sebenarnya siswa tidak malas membaca dilihat dari alasan yang dikemukakan responden, hanya 1 responden yang memilih fabel dengan jumlah kata yang sedikit. Selebihnya memilih cerita tersebut karena rasa penasaran akan cerita yang belum pernah ia dengar serta amanat cerita yang menarik. Jadi, jika siswa paham akan bacaan yang ia baca maka rasa malas dan bosan tidak akan muncul disaat membaca. Hasil interview 2 diperoleh ketika siswa tidak hanya membaca cerita tersebut, tetapi juga mereview dengan point yang terdapat dalam ishikawa fishbone dan memiliki hasil yang baik yaitu dengan teknik review ini setidaknya siswa mengetahui $75 \%$ dari isi bacaan yang telah mereka baca, hal tersebut diperjelas dengan hasil interview pada pertanyaan 3 dengan pernyataan responden yang mengungkapkan bahwa membaca saja tidak cukup tetapi perlu adanya review untuk mengetahui isi bacaan secara menyeluruh. . Hasil interview 4 dan 5 juga memiliki keterkaitan yang sama yaitu siswa memiliki respon yang positif terhadap teknik mereview ishikawa fishbone dan dapat membantu mereka dalam memahami bacaannya. 


\section{KESIMPULAN}

Pemahaman siswa terhadap bacaannya sangat berpengaruh, karena tanpa adanya pemahaman, informasi dari bacaan tidak akan mampu diserap. Sehingga, kegiatan membaca menjadi tidak berguna dan membosankan. Oleh karena itu mereview bacaan yang mampu meningkatkan minat siswa adalah hal yang terpenting. Mereview dengan teknik ishikawa fishbone hadir sebagai jawaban yang mampu meningkatkan bermacam

\section{REFERENSI}

Bose, T.K. 2012. „Application of Fishbone Analysis for Evaluating Supply Chain and Business Process - A Case Study on The ST James Hospitale $^{e e}$. International Journal of Managing Value and Supply Chains (IJMVSC), 3(2): 1724.Rosidi,Imron. 2015. Menguak Dunia Melalui Membaca. Surabaya: Iranti Mitra Utama: 1-110.

Easwaramoorthy, M. 2006. Interviewing for Research. Toronto: Imagine Canada: 6.

Krus, D. 2010. Thinking Tools for the Inquire Classroom. Australia: Education Service Publisher: 40.

M., Naasir. 2014. „Fishbone Strategy In Teaching Eglish in Indonesia: A aspek kognitif siswa diantaranya pengetahuan, vocabulary (kosa kata), grammar dan kreativitas. Hasil studi mengungkapkan bahwa teknik review ishikawa fishbone dapat membantu mereka dalam memahami bacaannya. Sehingga mereview menggunakan teknik ishikawa fishbone memiliki pengaruh yang positif terhadap kemampuan siswa dalam memahami bacaannya.

Tool Organizer For Learning EFL Reading ${ }^{\text {ee }}$. The Second International Conference on Education and Language Journal: 160.

Martin, J. 2006. „Fishy Story“. Jurnal Penyelidikan Tindakan Tahun (1): 29-41

Munawir Yusuf, d.k.k. 2003. Pendidikan Bagi Anak dengan Problema Belajar. Solo: Tiga Serangkai Pustaka Mandiri:

Wainwright,Gordon. 2007. How to Read Faster and Recall More. Oxford: How to Book: 37.

$\underline{\text { www.literasijabar.prov.go.id }}$ 